\title{
Computational Fluid Dynamics based Fuzzy Control Optimization of Heat Exchanger via Genetic Algorithm
}

\author{
Muammar Sadrawi \\ Mechanical and Industrial Engineering \\ Department, Syiah Kuala University, \\ Banda Aceh, Indonesia \\ muammarsadrawi@yahoo.com
}

Sarwo Edhy Sofyan

Mechanical and Industrial Engineering Department, Syiah Kuala University, Banda Aceh, Indonesia sarwo.edhy@unsyiah.ac.id

\author{
Jalaluddin Yunus \\ Mechanical and Industrial Engineering \\ Department, Syiah Kuala University, \\ Banda Aceh, Indonesia \\ jalaluddinyunus@unsyiah.ac.id
}

\author{
Maysam F. Abbod \\ College of Engineering, Design and \\ Physical Sciences, Brunel University \\ London, Uxbridge UB8 3PH, UK \\ Maysam.Abbod@brunel.ac.uk
}

Munawwar Khalil

Energieverfahrenstechnik und Umwandlungstechniken regenerativer Energien, TU Berlin, Berlin, Germany munawwar.khalil@campus.tu-berlin.de

Jiann-Shing Shieh

Department of Mechanical Engineering, Yuan Ze University, Chungli 32003, Taiwan

jsshieh@saturn.yzu.edu.tw

\begin{abstract}
This study evaluates the combination of computational fluid dynamics (CFD) and artificial intelligence (AI) algorithms in heat exchanger application. More specifically, fuzzy logic controller (FLC) is selected in the closed-loop control system. The sensor read by the FLC is based on the reading from the CFD meshing finite element method (FEM) discretization in order to solve the Navier-Stokes (N-S) equation. The controller output is the boundary condition of the CFD system (i.e heat flux). In this study, the CFD result will provide a predicted value approaching the set point. This system utilizes six rules for the controller. In order to evaluate the controller performance, several different set points are set. In addition, the genetic algorithm (GA) is set as the optimizer for the making of the sequence of the Mamdani triangular membership function. Finally, the GA is used to modify the membership function of the FLC. The total evaluation error for the FLC is $0.92{ }^{\circ} \mathrm{C}$ of the mean absolute error (MAE). Meanwhile, the GA-based FCL produces 0.78 ${ }^{\circ} \mathrm{C}$ has of MAE.
\end{abstract}

Keywords-computational fluid dynamics, artificial intelligence, fuzzy logic controller, genetic algorithm

\section{INTRODUCTION}

Artificial intelligence (AI) has been widely administered in considerable applications. It has been utilized for medical use such as arrhythmia problems [1, 2], anesthesia [3, 4] and blood pressure estimation [5]. Moreover, the AI also has been applied to energy systems [6-8], electromagnetic field [9] and shape optimization to increase the aerodynamics of the unmanned aerial vehicle [10].

Specifically for fuzzy, it has been used for clustering to deal with the highly unbalanced dataset in ensemble algorithm method [11]. Moreover, the fuzzy algorithm has also been used for the forecasting the stock index in time series evaluation [12]. In further, it also provides very powerful method for the control system application in anesthesia [13] and wearable sensor-based human rehabilitation [14].

Computational fluid dynamics (CFD) is a powerful numerical approach in solving the fluid system and also has been extensively implemented into massive fields. It has been used in aerodynamics-related field such as wind turbine [15] and refrigeration [16]. Meanwhile, the hybrid method, combination of genetic algorithm (GA), ANN and CFD, has also been studied in autonomous underwater vehicles [17]. furthermore, this study utilized GA to minimize the drag. In biomedical area, CFD was also used in cerebrovascular prob- lem in order to evaluate the performance of stent for the cerebral aneurysms analysis [18] and the evaluation of blood flow-related to the arrhythmia [19].

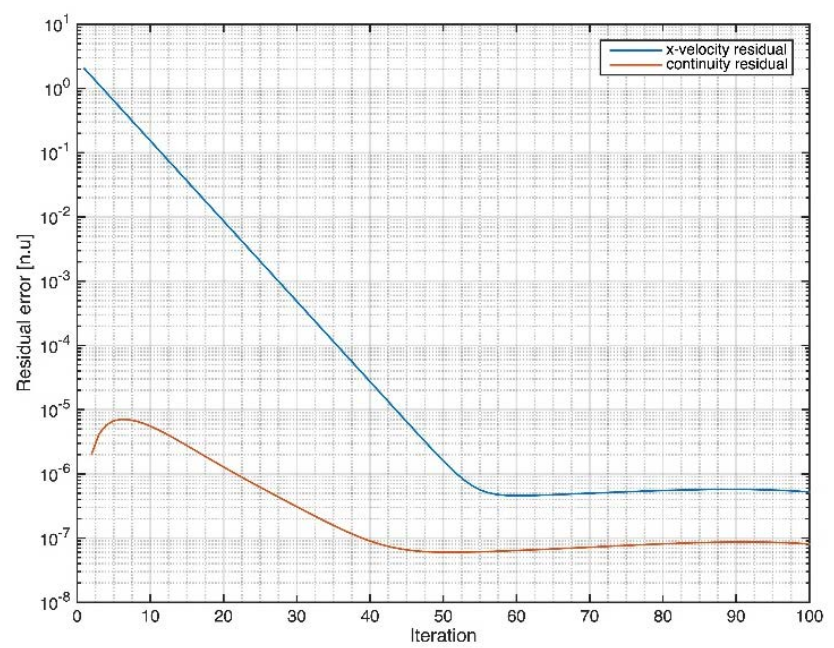

Figure 1. Navier-Stoker convergence.

Most of the FLC applications used sensor reading-based set point. However, this study's big contribution is combining the CFD application as the artificial sensor-based prediction value to several set points for the FLC. The advantages the CFD method is the ability to create massive vital set points in specific positions by the generated mesh. Therefore, this study has main purpose in optimizing the CFD-based closedloop fuzzy logic controller evaluation by the GA algorithm. The GA is utilized to set and adjust the error and error change membership functions with the mean absolute error generated from the system compared to the set point as the fitness function.

\section{METHODOLOGY}

The simulation data of the utilized heat exchanger size are $31 \mathrm{~cm}, 12 \mathrm{~cm}$ and $1 \mathrm{~cm}$, respectively for the length, width and tube radius. The system is an air-cooled heat exchanger. The system is assumed to be steady-state and limited only for laminar flow system. The Quickersim Toolbox for MATLAB [20] and its scripts, especially for the fuzzy logic controller, are utilized for this study. The Quickersim toolbox utilizes 
the finite element method (FEM) discretization method in order to solve the physical phenomena. The air velocities are $0.1 \mathrm{~m} / \mathrm{s}$ and $0 \mathrm{~m} / \mathrm{s}$, respectively for the horizontal and vertical velocities. The stop criterion is selected either 100 iterations or the lower than $1 \mathrm{E}-9$ residual. The relaxation value is set to 0.25 .

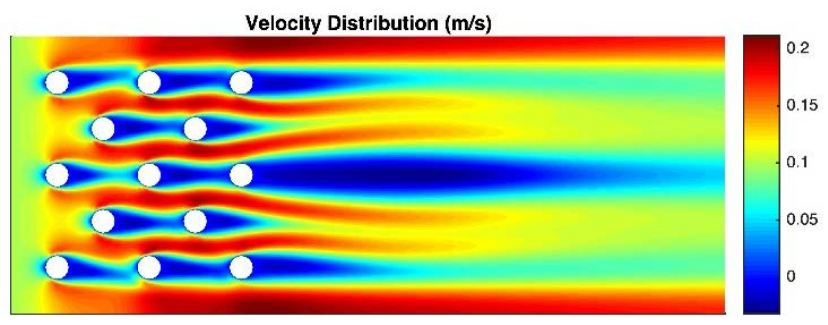

Figure 2. Navier Stokes velocity distribution.

The Navier-Stokes (N-S) equation is initially solved to get the velocity and pressure distribution of the system. The semi-log plot for the convergence of the N-S result can be seen in Fig. 1. The priority of this study is the $1 \mathrm{E}-9$ of the error. However, the model is stopped earlier after 100 iterations when the residual concludes to lower than 1-e6 which is still relatively acceptable. The velocity distribution is shown in Fig. 2.

The next step after the fluid-related computation is the assembly of the 2-D global diffusion matrix and global matrix scalar convection. In addition, the thermal boundary conditions are applied in the last step of the thermal boundary conditions. For more detail about these operations, it can be seen on [20].

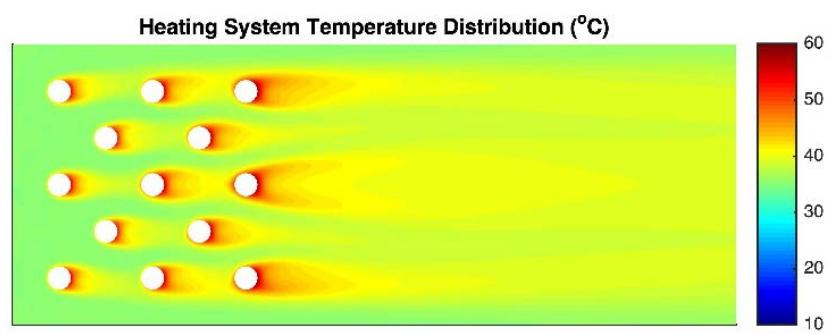

(a)

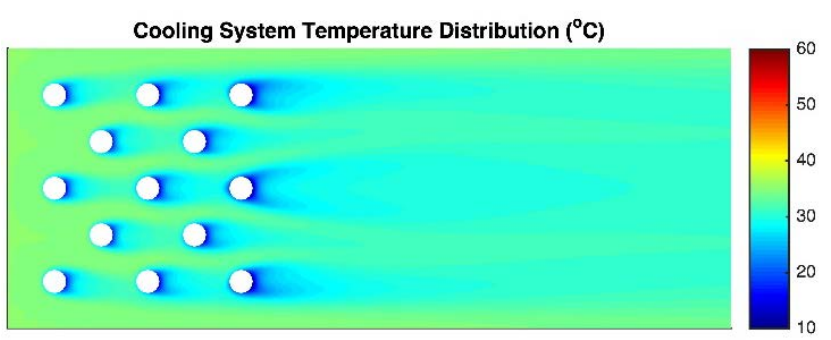

(b)

Figure 3. Heat flux effects. a) heating system. b) cooling systems.

In further, the thermal boundary condition is defined with the heat flux. The positive and negative heat fluxes mean the processes are under heating and cooling, respectively. These conditions also generate different phenomena to the tube surface temperature. The condition is shown in Fig. 3. Meanwhile, Fig. 4 shows the CFD-based evaluation area definition. Fig. 4a visualizes the distribution temperature. The green cir- cles are the evaluation area in the outlet of the system. Meanwhile, Fig. 4b is the temperature distribution of the outlet temperature for the evaluation area. The maximum value of the green circles is set as the specific controlled temperature of the system. These temperature values are fully related to heat flux generated from inside the tube.

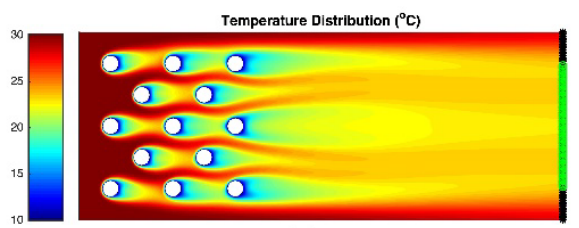

(a)

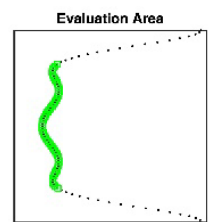

(b)
Figure 4. Thermal boundary condition. a) Temperature distribution. b) Evaluation area.

Therefore, closed-loop fuzzy logic controller with the heat flux, for both output and the boundary condition of the system, Sugeno skeleton membership function is set. Furthermore, for the inputs, the Mamdani triangular membership function is used. The error membership functions are distributed into six levels, which are negative very large (NVL), negative large (NL), negative normal $(\mathrm{NN})$, negative small (NS) negative very small (NVS) and zero (Z). Meanwhile, the error change membership function is shared into three levels; negative large (NL), zero (Z) and positive large (PL). The system is minimized into a six-rule controller as can be seen in Table 1 . The evaluation error is defined by 15 seconds after the set point to the end of the system or another set point change. This condition can be described in another way by the controller only has this period to reach the set point.

Table 1. Fuzzy logic controller rules

\begin{tabular}{|l|c|c|c|c|}
\hline \multirow{2}{*}{ Heat Flux $(\mathrm{W} / \mathrm{m} \wedge 3)$} & \multicolumn{3}{|c|}{ Error Change $\left({ }^{\circ} \mathrm{C} / \mathrm{Sec}\right)$} \\
\cline { 3 - 6 } & $\mathrm{NVL}$ & $\mathrm{VL}$ & & \\
\hline \multirow{5}{*}{ Error $\left({ }^{\circ} \mathrm{C}\right)$} & $\mathrm{NL}$ & $\mathrm{L}$ & & \\
\cline { 2 - 5 } & $\mathrm{NN}$ & & $\mathrm{N}$ & \\
\cline { 2 - 5 } & $\mathrm{NS}$ & & $\mathrm{N}$ & \\
\cline { 2 - 5 } & $\mathrm{NVS}$ & & & $\mathrm{VS}$ \\
\hline & $\mathrm{Z}$ & & & $\mathrm{Z}$ \\
\hline
\end{tabular}

The next step is the optimization. The genetic algorithm (GA) is selected as the optimizer. Generally, GA hast three major parts; reproduction, crossover and mutation. The reproduction is the step that produces single or multiple random chromosomes to build the population. Crossover, normally, is the mating between some parts of a population to another one. In further, the mutation is a change of a single or multiple bit in the chromosome in populations. This study separates the 18-bit and 9-bit chromosomes for the error and error change, respectively. Furthermore, four-population system is set for the structure to reduce the computation.

The GA started by initialization of the random populations. After the initialization, the fitness function calculation is directly applied to sort the population based on the minimum mean absolute error (MAE) by comparing the controlled output to the set point. The best chromosome is stored, 
meanwhile the others are discarded. The crossover is separately performed for each input by swapping saved chromosome; nine-to-nine bits are parted for the error input and fiveto-four bits for the error rate. The following step is the fitness function evaluation as well. Furthermore, the squared of 0.1 mutation rate is utilized and also followed by the calculation of the fitness function. Temporarily, the system has three populations; the initial part, crossovered, and the mutated chromosomes. In order to reform the 4-population system, another random chromosome is produced. Finally, the sorting procedure is conducted based on the minimum MAE in order to have the best candidate of the system. The flowchart of the GA-based FCL can be seen in Fig. 5.

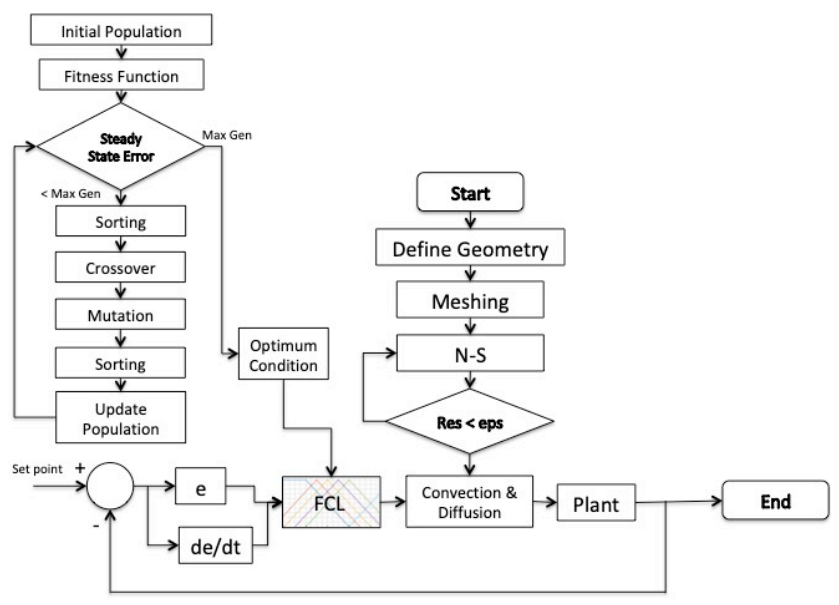

Figure 5. Genetic algorithm-based fuzzy logic controller flowchart.
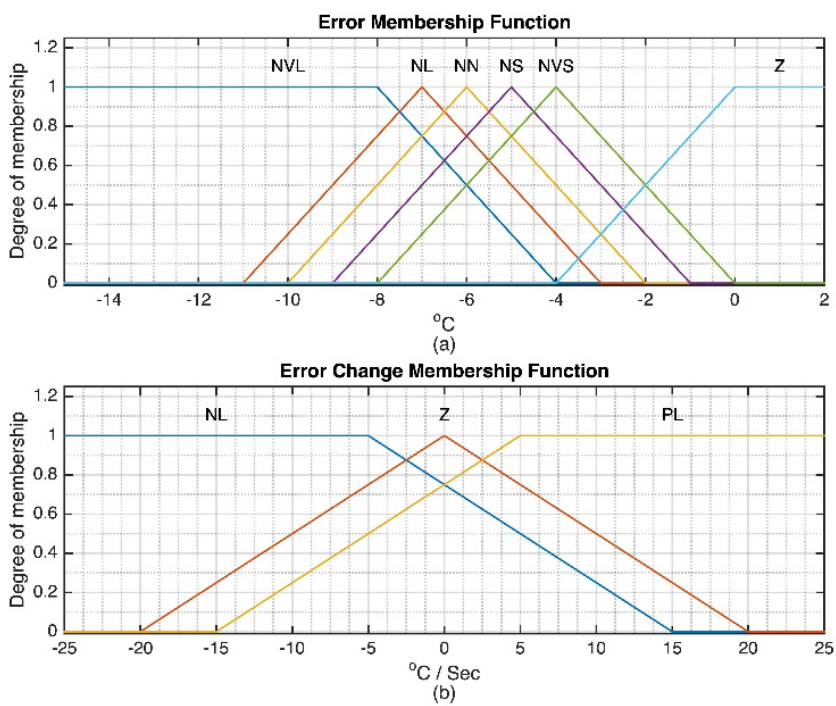

Figure 6. Fuzzy logic controller membership function. a) Error membership function. b) error change membership function.

\section{RESULT AND DISCUSSION}

The main results between the CFD-based FLC and GAtuned FCL are investigated. The performance of the controller is evaluated by three set point changes from the relatively small to relatively big changes in 2 minutes. Initially, the CFD-based FLC is presented. The membership function of the FLC is shown in Fig. 6. The error and error change membership functions can be seen in Fig. 6a and Fig. 6b. The
Sugeno skeleton membership function of the output can be seen in Fig. 7.

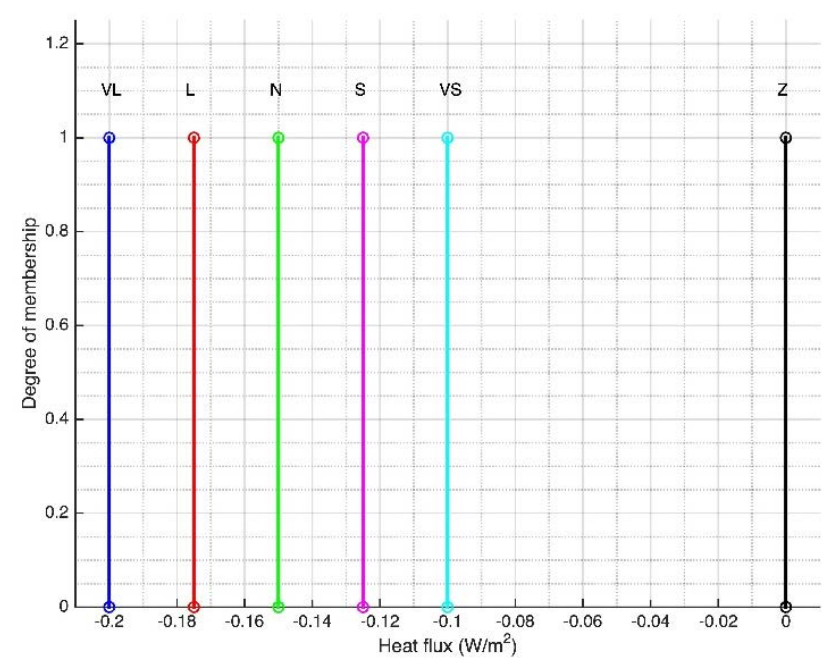

Figure 7. Output membership function

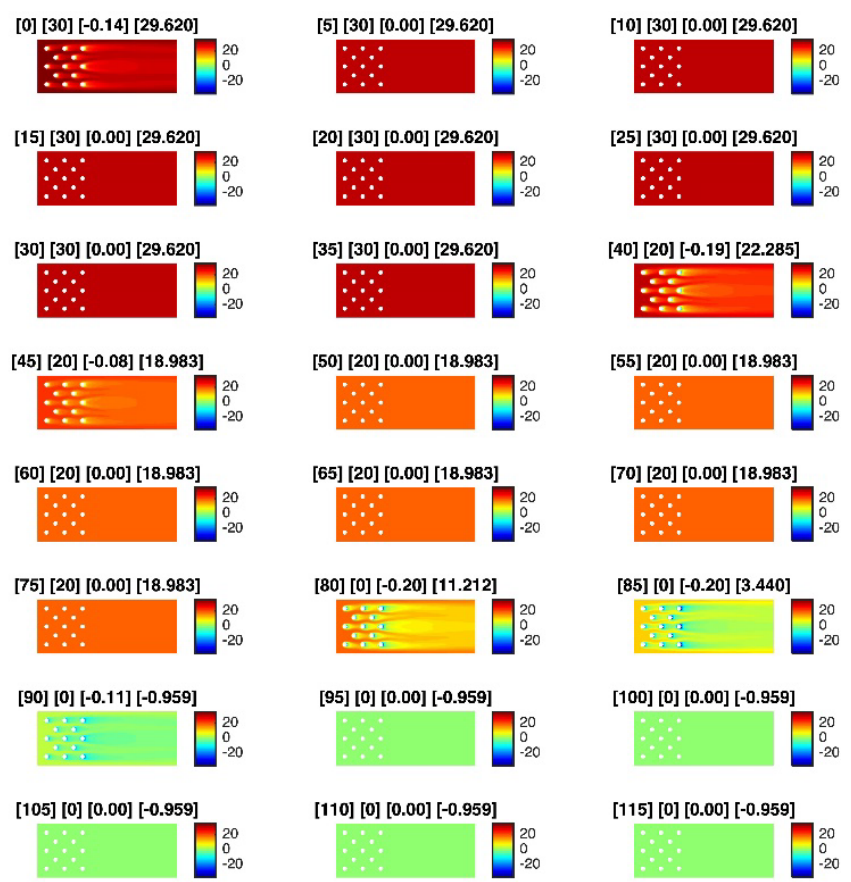

Figure 8. CFD-based FCL result.

The CFD-based performance can be seen in Fig. 8. The format of this image; time, set point, transferred heat flux and controlled temperature. Furthermore, the initial room temperature is $35^{\circ} \mathrm{C}$. The first set point is set to $30^{\circ} \mathrm{C}$. It can be seen that the controller supplies $-0.14 \mathrm{~W} / \mathrm{m}^{2}$ reduce the temperature steadily to $29.62{ }^{\circ} \mathrm{C}$, generating overshoot error about $0.38{ }^{\circ} \mathrm{C}$ error. Meanwhile, the second set point is $20{ }^{\circ} \mathrm{C}$, the controller initially generates $-0.19 \mathrm{~W} / \mathrm{m}^{2}$ to reach $22.28{ }^{\circ} \mathrm{C}$. However, due to the set point is not reached yet, the additional $-0.08 \mathrm{~W} / \mathrm{m}^{2}$ is provided. Nevertheless, it has overshoot $1.02{ }^{\circ} \mathrm{C}$ error. The final set point is adjusted deeper to $0{ }^{\circ} \mathrm{C}$. In this condition, initially, the heat flux is transferred to -0.2 $\mathrm{W} / \mathrm{m}^{2}$ in 10 seconds. It reaches 11.21 and $3.44{ }^{\circ} \mathrm{C}$, respectively. The reduced $-0.11 \mathrm{~W} / \mathrm{m}^{2}$ heat flux is then supplied to reach $-0.96{ }^{\circ} \mathrm{C}$ that generates $0.96{ }^{\circ} \mathrm{C}$ overshoot error. Eventually, the total evaluation error is $0.92^{\circ} \mathrm{C}$. 


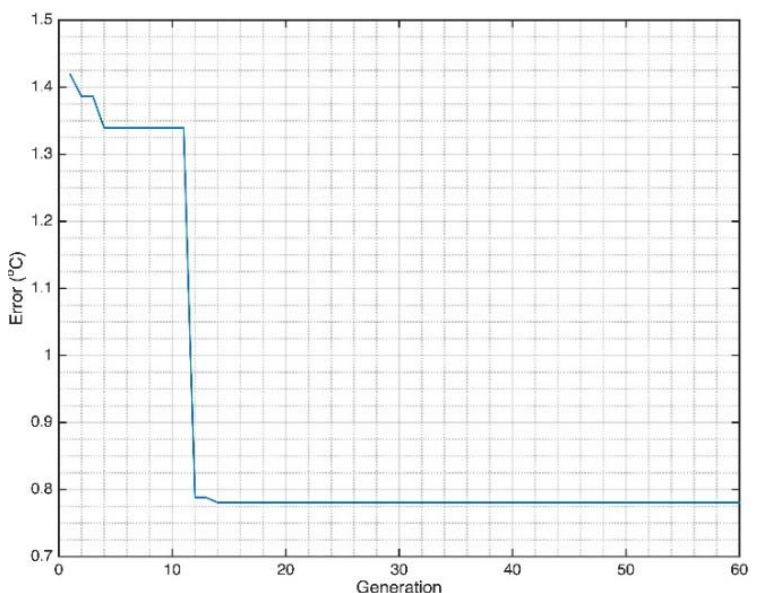

Figure 9. Fitness function of genetic algorithm.
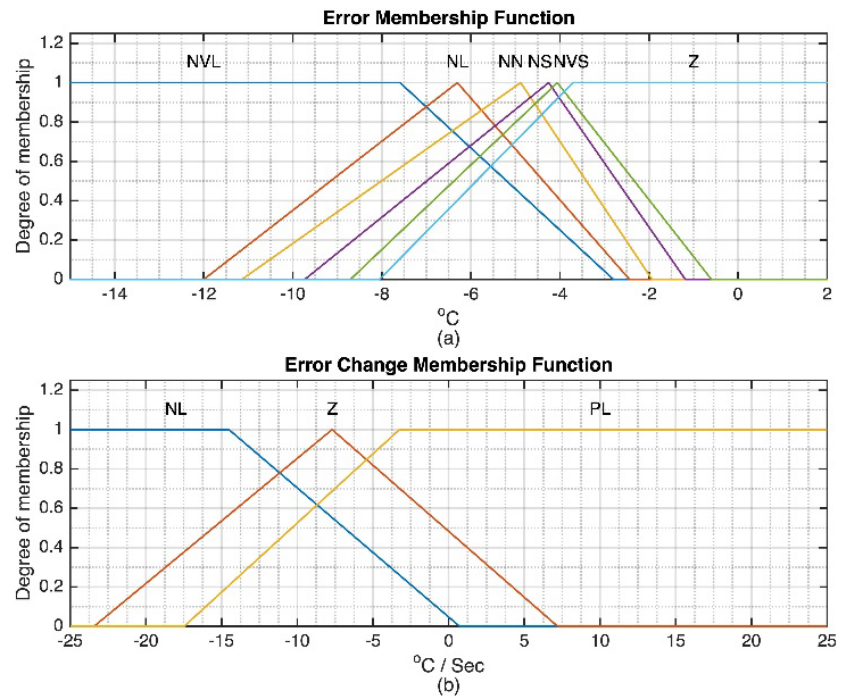

Figure 10. Genetic algorithm-based fuzzy logic controller membership function. a) Error membership function. b) error change membership function.

The evaluation of the GA-based FLC can be seen in the following figures. Fig. 9 shows the convergence of the GA fitness function and its generation. In the initial generations, the fitness function achieves higher than the non-optimized FLC and gradually reduces. However, in about the $10^{\text {th }}$ generation, the system has a remarkably reduced condition, generating about lower-than $0.8{ }^{\circ} \mathrm{C}$ error. The error continues to slightly reduce in about $15^{\text {th }}$ generation. This condition is held until 60 generations to conclude the $0.78{ }^{\circ} \mathrm{C}$ error.

By having a good fitness function, the generated membership function can be seen in Fig. 10. The error membership function system tends to be unsymmetrical triangular membership functions and the "Zero" membership functions shifts to the left side compared non-GA FLC membership function. Meanwhile, the error change membership function relatively has less width for the "Zero" membership function and also the shift to the left side for all of the membership functions.

The controller result of these membership function can be seen of Fig. 11. Initially, the $-0.09 \mathrm{~W} / \mathrm{m}^{2}$ is transferred to get $31.5{ }^{\circ} \mathrm{C}$. Subsequently, another $-0.03 \mathrm{~W} / \mathrm{m}^{2}$ is supplied to reach $30.28^{\circ} \mathrm{C}$ that has steadily $0.28^{\circ} \mathrm{C}$ undershoot error. The next set point is $20^{\circ} \mathrm{C}$. In this condition, the system adapts with transferring $-0.17 \mathrm{~W} / \mathrm{m}^{2}$ and additional $-0.12 \mathrm{~W} / \mathrm{m}^{2}$ to reach $19.34{ }^{\circ} \mathrm{C}$ and has $0.66{ }^{\circ} \mathrm{C}$ of overshoot error. Finally, the last set point, $0{ }^{\circ} \mathrm{C}$, the initial heat flux supplied by GAFLC are $-0.2 \mathrm{~W} / \mathrm{m}^{2},-0.05 \mathrm{~W} / \mathrm{m}^{2}$ and $-0.03 \mathrm{~W} / \mathrm{m}^{2}$, respectively to have $0.59{ }^{\circ} \mathrm{C}$ and has $-0.59{ }^{\circ} \mathrm{C}$ of undershoot error. Totally, the GA-tuned FLC produces $0.78^{\circ} \mathrm{C}$ of error.
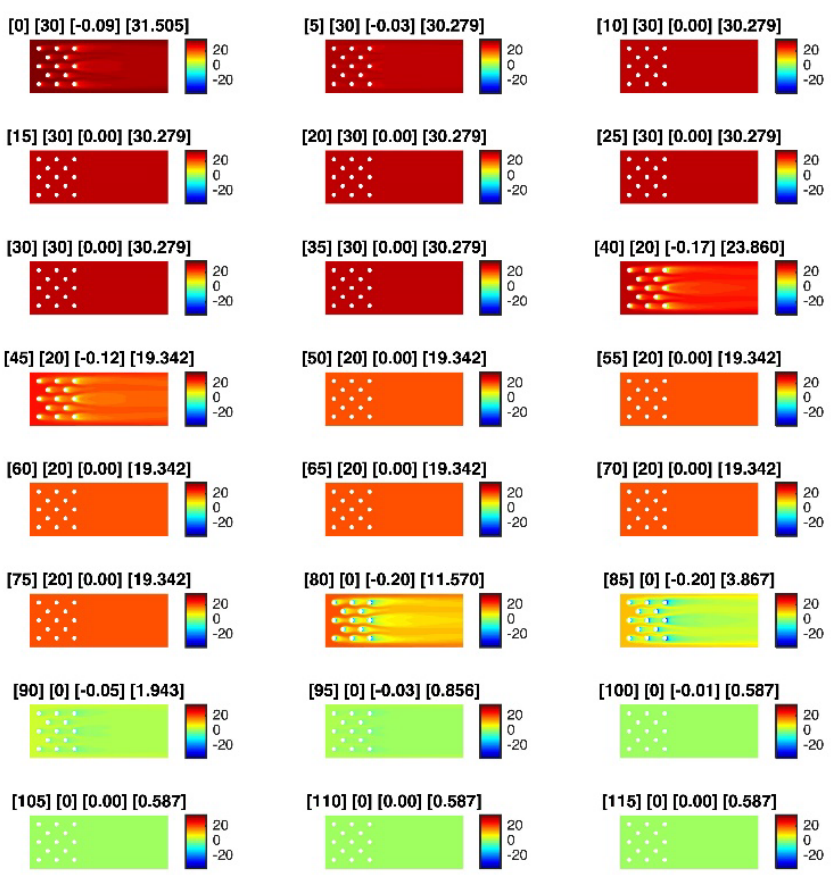

[100] [0] [-0.01] [0.587]

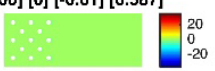

[110] [0] [0.00] [0.587]

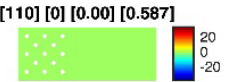

[115] [0] [0.00] [0.587]

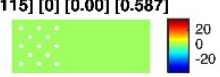

Figure 11. CFD-based GA-tuned FCL result.

The comparison between FLC and GA-based FLC can be seen in Fig. 12. Fig. 12a shows the controller performance from FLC and GA-based FLC to the set point. As can be seen, the GA-FLC produces better result in approaching the set point. Meanwhile, Fig. 12b displays the generated error between two controllers to the set point. The three different temperatures are set in order to see the performance in dealing with different changes of the set points. The GA-based FLC generates better result compared to the FLC. In further, the supplied heat flux can be seen in Fig. 12c. It can be seen that initially the GA-based FCL provides a lower supply to the system for the lowest change which is $5^{\circ} \mathrm{C}$. Furthermore, when the $10{ }^{\circ} \mathrm{C}$ change, the GA-based FCL adapts more smoothly in distributing the heat flux. Meanwhile, the FCL forces the heat flux to a relatively deep change. Finally, for the highest change of the set point, the GA-based FCL is in a better step in dealing with the overshoot. In addition, the GAbased FCL needs to slow down the heat flux more rapidly due to the set point is about to be achieved.

\section{IV.CONCLUSION}

This study investigates the fuzzy logic controller with the evaluation of computational fluid dynamics. The genetic algorithm as the optimization method is applied to tune the membership function of the fuzzy logic controller. The result shows the optimized membership function of the fuzzy logic controller overcomes the non-optimized fuzzy controller. 

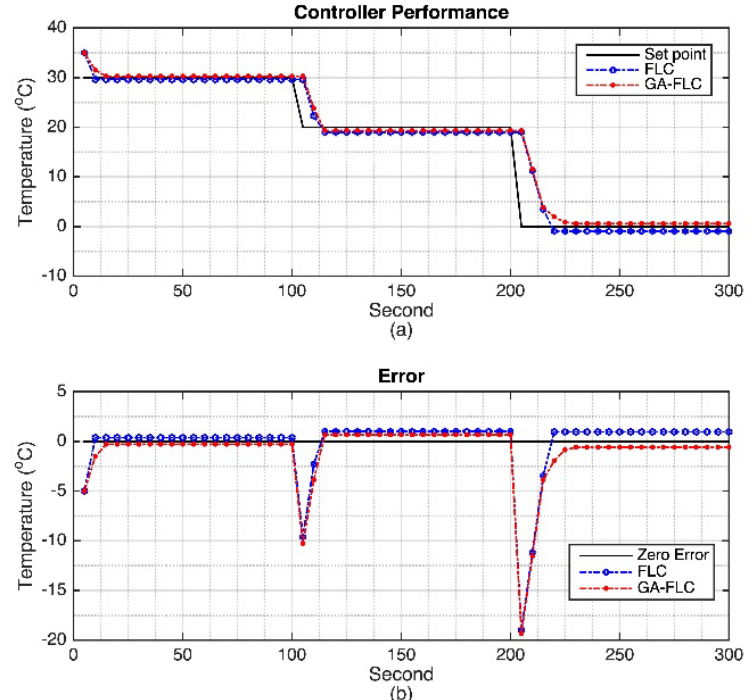

(b)

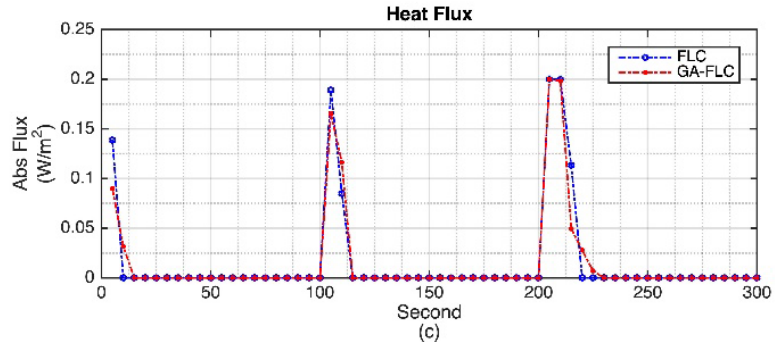

Figure 12. Comparison between fuzzy logic controller and genetic algorithm-based fuzzy logic controller. a) controller performance. b) Generated error and c) Supplied heat flux.

\section{REFERENCES}

1. P. Rajpurkar, A.Y. Hannun, M. Haghpanahi, C. Bourn, and A.Y. Ng, "Cardiologist-level arrhythmia detection with convolutional neural networks,” arXiv preprint arXiv:1707.01836, 2017.

2. M. Sadrawi, C.H. Lin, Y.T. Lin, Y. Hsieh, C.C. Kuo, J. Chien, K. Haraikawa, M. Abbod, and J.S. Shieh, "Arrhythmia evaluation in wearable ECG devices,” Sensors, vol. 17, p. 2445, 2017.

3. M. Sadrawi, S.Z. Fan, M.F. Abbod, K.K. Jen, and J.S. Shieh, "Computational depth of anesthesia via multiple vital signs based on artificial neural networks,” BioMed research international, vol. 2015, 2015.

4. J.R. Huang, S.Z. Fan, M. Abbod, K.K. Jen, J.F. Wu, and J.S. Shieh, "Application of multivariate empirical mode decomposition and sample entropy in EEG signals via artificial neural networks for interpreting depth of anesthesia,” Entropy, vol. 15, pp. 3325-3339, 2013.

5. M. Sadrawi, J.S. Shieh, S.Z. Fan, C.H. Lin, K. Haraikawa, J.C. Chien, and M.F. Abbod, "Intermittent blood pressure prediction via multiscale entropy and ensemble artificial neural networks,” In 2016 IEEE EMBS Conference on Biomedical Engineering and Sciences (IECBES), pp. 356-359, December 2016.

6. K.Y. Bae, H.S. Jang, B.C. Jung, and D.K. Sung, "Effect of Prediction Error of Machine Learning Schemes on Photovoltaic Power Trading Based on Energy Storage Systems,” Energies, vol. 12, p. 1249, 2019

7. W. Al-Kouz, S. Al-Dahidi, B. Hammad, and M. Al-Abed, "Modeling and Analysis Framework for Investigating the Impact of Dust and Temperature on PV Systems' Performance and Optimum Cleaning Frequency,” Applied Sciences, vol. 9, p. 1397, 2019.

8. M. Fayaz, H. Shah, A.M. Aseere, W.K. Mashwani, and A.S. Shah, "A Framework for Prediction of Household Energy Consumption Using Feed Forward Back Propagation Neural Network. Technologies, vol. 7, pp. 30, 2019.

9. G. Wang, W.H.Kim, G.S. Kil, D.W. Park, and S.W. Kim, “An Intelligent Lightning Warning System Based on Electromagnetic Field and Neural Network,” Energies, vol. 12, p.1275, 2019.

10. Y. Azabi, A. Savvaris, and T. Kipouros, “Artificial Intelligence to Enhance Aerodynamic Shape Optimisation of the Aegis UAV,” Machine Learning and Knowledge Extraction, vol. 1, pp. 552-574, 2019.

11. M. Sadrawi, W.Z. Sun, M. Ma, Y.T. Yeh, M. Abbod and J.S. Shieh, "Ensemble Genetic Fuzzy Neuro Model Applied for the Emergency
Medical Service via Unbalanced Data Evaluation,” Symmetry, vol. 10, p.71, 2018.

12. J.A. Jiang, C.H. Syue, C.H. Wang, J.C. Wang and J.S. Shieh, “An Interval Type-2 Fuzzy Logic System for Stock Index Forecasting Based on Fuzzy Time Series and a Fuzzy Logical Relationship Map,” IEEE Access, 6, pp. 69107-69119, 2018.

13. Y.X. Liu, F. Doctor, S.Z. Fan and J.S. Shieh, "Performance analysis of extracted rule-base multivariable type-2 self-organizing fuzzy logic controller applied to anesthesia,” BioMed research international, 2014.

14. S. Taslim Reza, N. Ahmad, I. Choudhury and R. Ghazilla, “A fuzzy controller for lower limb exoskeletons during sit-to-stand and stand-tosit movement using wearable sensors,” Sensors, 14(3), pp. 4342-4363, 2014.

15. Y. Li, Y. Jiang, and F. Feng, "Scaling Method of the Rotating Blade of a Wind Turbine for a Rime Ice Wind Tunnel Test,” Energies, vol. 12, pp. 627, 2019.

16. P.D. Gaspar, L.C. Gonçalves and R.A. Pitarma, "Detailed CFD modelling of open refrigerated display cabinets,” Modelling and Simulation in Engineering, pp .9, 2012.

17. W. Tian, Z. Mao, F. Zhao and Z. Zhao, "Layout optimization of two autonomous underwater vehicles for drag reduction with a combined CFD and neural network method,” Complexity, vol. 2017, 2017.

18. B. Catalán-Echeverría, M.E. Kelly, L. Peeling, D. Bergstrom, X. Chen, and M. Malvè, "CFD-Based Comparison Study of a New Flow Diverting Stent and Commercially-Available Ones for the Treatment of Cerebral Aneurysms,” Applied Sciences, vol. 9, p. 1341, 2019.

19. G.M. Bosi, A. Cook, R. Rai, L.J. Menezes, S. Schievano, R. Torii and G.B. Burriesci, "Computational fluid dynamic analysis of the left atrial appendage to predict thrombosis risk," Frontiers in cardiovascular medicine, 5, p. 34, 2018.

20. https://www.mathworks.com/products/connections/product_detail/quickersim-cfd-toolbox.html (accessed on April 18th, 2019). 